\title{
Stylized Tendency of Scene Design in Digital Games-Take Gothic and Surrealism for Example*
}

\author{
Lijun Wang, Xiao Dou \\ School of Architecture and Design, Beijing Jiaotong University, Beijing, China \\ Email: wanglijun@bjtu.edu.cn
}

Received 2 February 2015; accepted 13 April 2015; published 15 April 2015

Copyright (C) 2015 by authors and Scientific Research Publishing Inc.

This work is licensed under the Creative Commons Attribution International License (CC BY). http://creativecommons.org/licenses/by/4.0/

(c) (i) Open Access

\begin{abstract}
In this paper, taking the scene design in gothic style for Alice: Madness Return and the scene design in surrealism for Samorost 1-3 for examples, authors analyze the stylized tendency of scene design in digital game. The stylized game scene design sends out avant-garde design thinking, which provides infinite creative potential and aesthetic view to the game design, and which makes the game scene design presents an aesthetic concept with rich individual characters and cultural accumulation.
\end{abstract}

Keywords

Digital Game, Stylized, Scene Design, Gothic, Surrealism

\section{Introduction}

Nowadays, there are multitudinous digital game ${ }^{1}$ works. Traditional Massively Multiplayer Online Role Playing Games and web-games are dominated by western magic or eastern swordsman style. They are produced by 3D or 2D digital software with simulated visual model and texture as well as scene and ambience close to reality. In fact, when a great digital game works come out, the first reaction of a lot of players is to pay attention on "is it funny" or "is it attractive". It is obvious that interest and visual sense of games occupy important positions in the players' mind. The most crucial function of digital games is creating new concept, realistic visual effect, consistent style and distinctive virtual world in order to attract players. As the development of digital games and the

"This paper is one of the outcomes of Research on Frame of the Compound Specialty of Digital Media Art (Item number: 2011JBM316).

This paper is one of the outcomes of the State Scholarship Fund sponsored by China Scholarship Council (Item number: 201307095001). 
increasing number and levels of players, traditional and single digital game visual style cannot satisfy the players' increasing enthusiasm.

As the most important part of digital game creation, scene design in digital games is one of the most direct communication points between games and players. The digital game is virtual movement behavior and scene design is to construct virtual space. Thus, scene design plays a pivotal role of setting general tone and creating the environment and ambience in digital game design. The quality of scene design directly connects with that of games. Along with the development of game industry and an increasing amount of digital games, players have been gradually tired of similar scene design effects. Designers began to pursue more attractive style of game scene design with more features. Arisen out of that, stylized tendency of game scene design is usually of two characteristics.

First, time background of games is vague. Time factors influencing visual effect of games can be found easily such as costume and make-up style, architecture style and ambience presenting of scene space as well as furnishings and props with brand of times. Most of game planners frequently define a clear time background or specific location according to the starting point and experience demand in order to enable designers to find related architectures, ornaments and props and to perform the distinct ambience in accord with specified era. Thus, time background is the primary factor deciding scene style in traditional game design. These time features seems to be very important for the game is to simulate activity experience of real world in virtual space. What's more, redoubling efforts on creating sense of times is necessary to make players feel personally on the scene, e.g. the game series Romance of Three Kingdom. However, it is the definite time background that limits designers' imagination and is inimical for innovation development of game visual effect. In stylized game scene design, it becomes the key point of design that the time background should be weakened to make the imagination unfettered. Without the time background, stylized game scene design requires superb artistic imagination and overall control to blend exaggeratedly architectures, ornaments, props and the other parts of the scene in the unified style and ambience.

Second, artistic style is unified and definite. Stylized game scene design shows great originality and unique artistic style which is easy to trace the prototype of art genre. Game approach is connected with selected art style. The reason is the starting point and thinking process of stylized games are different from that of traditional commercial games, i.e. for the later ones, the process of seeking design inspiration is longitudinal and they decide their artistic style of scene after studying the form of current popular games; but for the former ones, the process of looking for inspiration is transverse and they select the most suitable style from various art genres to use in the game design after thinking about the visual arts. This article will take two stylized scene design games influenced by gothic art and surrealism respectively for example and analyze stylized tendency of digital game scene design abroad.

\section{Alice: Madness Return and Gothic Style}

The game Alice: Madness Return is an action-venture game produced by Spicy Horse Games in 2011 and published by EA (Electronic Arts Inc.). From scenes and roles to background music and promotional video, the whole game is filled by deep gloom and horrible gothic style, which arose in Europe during the Middle Ages when the classical civilization was between the decline and revival. At that time, such an artistic style was mainly used in architecture to present the mystery of historical architectures like churches, castles and so forth featured by repeated vertical lines extending in the architecture styles. Gothic style was also found in sculpture, painting as well as arts and crafts with exaggerated, peculiar and complex traits. Nowadays, the widely mentioned gothic style mostly refers to Gothic Revival arisen from the middle 18th century to that of 19th century. Gothic Revival is excavating medieval gloomy ambience from historical tomb, innovating the horrible and gloomy element embodied by music, literature, costume and movie and gradually forming into present gothic style that we are familiar with. It is featured by decadent and horrible elements and typified by vampires, crosses, black eye circles, pale faces, and skeletons etc. which are frequent elements used in digital art works with gothic style. Among that, misused materials like vampires and deaths in literature field are subtle to endow the word Gothic with misery and gloom connotation typified by dark style. In 1980's, the emerging gloomy gothic rock had deep impact on plasticiens and designers in various fields. A number of artists were affected by gothic literatures and rock music. They applied the favor of gothic style into their works, e.g. the serial films directed by Tim Burton, a talented American director, Edward Scissorhands, Sleepy Hollow, Sweeney Todd: The Demon Barber of Fleet- 
Street, Corpse Bride, Frankenweenie, are proper blend of humor, love and horror; Japanese animations and cartoon works are popularized for their gothic Lolita style; also the mentioned digital game Alice: Madness Return are directed in gothic style.

The setting of Alice: Madness Return overturned the fancy and warmth of traditional fairy tales. The leading role Alice is never the blonde girl of the conventional comics and films but a slim, pale, and black haired gloomy girl with sharp eyes and big black eye circles. She was defined as a psychotic girl escaping from mental hospital. Her family died in a fire and she herself lost her memory. Alice shuttled between reality and wonderland in her fancy in order to find out her memory and the real reason of her family members' deaths. The scene of Alice: Madness Return was made of both real world telling the setting of story and fantasyland where the game are playing while Alice tries to seek her memory. The combination of reality and fancy make the overall scene style to be a unique mixed space of fiction and reality. Such a mixed space is an organic uniform of realism and imagism. The plots, scenes and space levels of real world are all fewer and the whole structure is simple. However, the fantasy world of Alice takes up more plots, scenes as well as space levels and the structure is complex. In some crucial scenes with turning point, considering player's emotion, immerse, space environment and clear and complete structure are combined with multiple layers of dense architecture, interweaving small spaces and mysterious gloomy unfrequented environment so that the players can get a stronger sense of horror. That conforms to human's psychological reaction for anyone will fear in a new environment. It is generated by unknown about the new environment and fear of sudden danger somewhere that may hurt himself. The more complex the scene is, the more chances dangers have to happen, the stronger the fear is. Meanwhile, there is a weird paradox that human beings will be more curious and explorative about and long to approach what they are afraid of. It is like a timid person watching thrillers. He frequently covers his face with hands for fear of the grisly scenes while peeping between fingers. He is never tired of watching thrillers one after another like that for joy. The paradox psychology is either a process of transforming from fear of the horror to approaching, understanding, overcoming and confronting it, or a course of dispelling fear, obtaining new knowledge as well as relieving the tense, depression and pressure. The course can stimulate the secretion of adrenaline that generates sense of excitement. That is why the grisly scene is easy to attract the players on psychological experience of terror and to make them relieving pressure and pursuing stimulation.

For the gothic images, pale faces, big black eye circles are necessary. The striking feature originated from medieval evil-vampire. Alice in the game inherits the feature of black straight hair, pale face, big eyes and black eye circles. The blood appeared repeatedly on her body adds bloody atmosphere to the game which is agree with bloodthirsty character of vampire. The vampire-related blood, death, tomb elements and the other dark, somber, bloody and hideous scenes are everywhere. The modeling of overall architectures is dominated by lofty and thin towers with pinnacles conforming to the gothic $\mathrm{x}$ architecture style with longitudinal lines. Surrounded by climbing plants with threatening branches and leaves like monster's tentacles, the single building has complicated structure. The primary colors are black and dark grey in order to express the gloomy and terrible ambience. Subsidiary colors in some parts are high-purity bright red, yellow and grass green which enhance visual impact and color contrast of the overall modeling. The indoor scene design is featured by black and white floor tiles and slender and narrow corridors. The black and white floor tiles like chessboard repeatedly setting in messy spaces cannot make player calm down but evoke faint anxiety about single graph order. Chess arose in the middle ages and is a typical representative of medieval culture and often appears in fantasy films. So the floor tiles are endowed with a sense of history and magic; In the design of outdoor scene, the typical gothic style is its core of design, through the tower with a blood red window spire, the dangling buildings and the combination of chaotic space effect create a horrible, ferocious and distorted special aesthetic feeling, and let the player produce a fearful and curious mind in the process of playing games (Figure 1). Controlled by this mentality, the players will be dedicated to the environment the game created and curious about the monsters emerged every time, and feel fearful and strange for each new scene. Therefore, after closing the game, they may have an aftertaste for a long time, which is the ultra-strong game immersion brought by the stylized scene design of Alice: Madness Return.

\section{Samorost 1-3 and Surrealism}

Samorost 1-3 is an independent game designed by Jakub Dvorsky, who is a webpage animation designer. When designing the game, he was just a student in Prague Art Architecture and Design College. The game has three versions, the surreal image and style also gradually become more and more mature, especially the third version, 


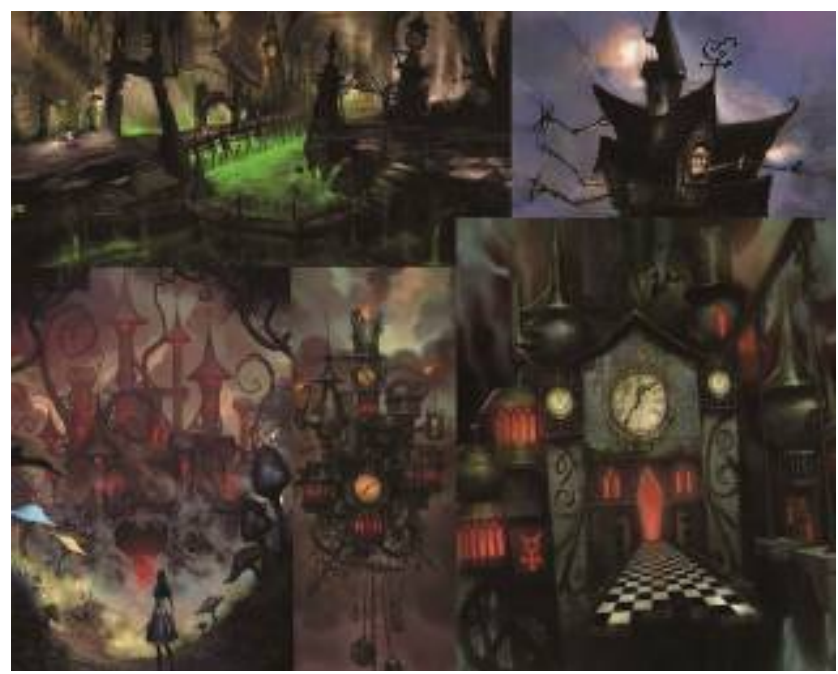

Figure 1. The scene plan of digital games Alice: Madness Return.

has an effect on many later games, such as Machinarium. The game's scene and modeling belong to psychedelic and dream-filled spatial formations, and the designer took the subjective consciousness as the basis of creation. Through the symbolic and metaphorical application of model, color, environment and other elements, the game shows the unique, fantastic, surrealistic additional features, at the same time, the grasp for the integrity of the game scene and modeling style is especially outstanding, which makes each modeling design of different shapes put together and have a more unexpected visual effect.

Surrealism, which was prevalent in the genre of literature and art during the period of two world wars, has been influenced by Freud's psychoanalysis theory. It dedicated to find the human's subconscious psychology, advocated to abandon logical and orderly real image based on the experience memory, while presented the image world in people's deep psychology, and tried to fuse the reality and instinct, subconscious especially dream experience. The paintings of Dali, Miro and other surrealist painters, who are dreamy and idealistic, explore people's imagination and unconscious. Among them, Dali's painting is a kind of dream and illusion in disguise, full of sex, death, anomaly, non-irrationality and other themes. He is used to adopt the illogical method and the method of paralleling things to translate the inspiration generated by emotion stimulation into a creative process, add the absurdity and weirdness of his heart to the outward objective world, twist the things that people are familiar with, confirm with elaborate means, and make the illusion have an authenticity color, so the treatment of art is very subjective.

The game scene of Samorost 1-3 completely inherits the surrealist painter-Dali's unstable, irrational, illogical artistic style and modeling features of arranging things. In Dali's works, the body of picture is distorted and weird, but the modeling of these objects is exquisite. Like Dali's works, the scene background of Samorost 1-3 is a meaningless or nonexistent null space, which is empty and lonely. Its subjects also absorbed the feature, the characters and main objects are floating in the air, the modeling of the main objects is very irregular, and it seems that cannot fine its prototype in real life, but its strong modeling is strong, depiction is meticulous. In terms of color, it mostly uses natural and partial gray color, which is real or imagined and lets people feel familiar and strange, and the whole scene modeling presents a kind of subjective aesthetic feeling. Being completely different from the modeling of commercial games which focus on visual effects and grand scene, the expression and imagination of the game scene of Samorost 1-3 are definitely outstanding, which we can see in some manuscripts. The structure and hierarchy of the scene design pictures are clear, there is no difference between the atmosphere drawings of the colorized drafts and the game's finally effect, and the color is rich and luxuriant but unified on the basis of a tone. The chosen scenes are mostly some long shots, which let players see the surroundings to a maximum extent (Figure 2). The maverick mystery modeling and environment are easy to be suspected, estimated and speculated by people so that they will inquire deeply or have a try regardless of the bans, and thus the main objects get a satisfactory of self-affirmation.

Freud once said, "the children behaviors of game are like an imaginative writer at this point: he creates a world of his own or, more precisely, he rearranges his everything in heaven and earth according to his favorite 


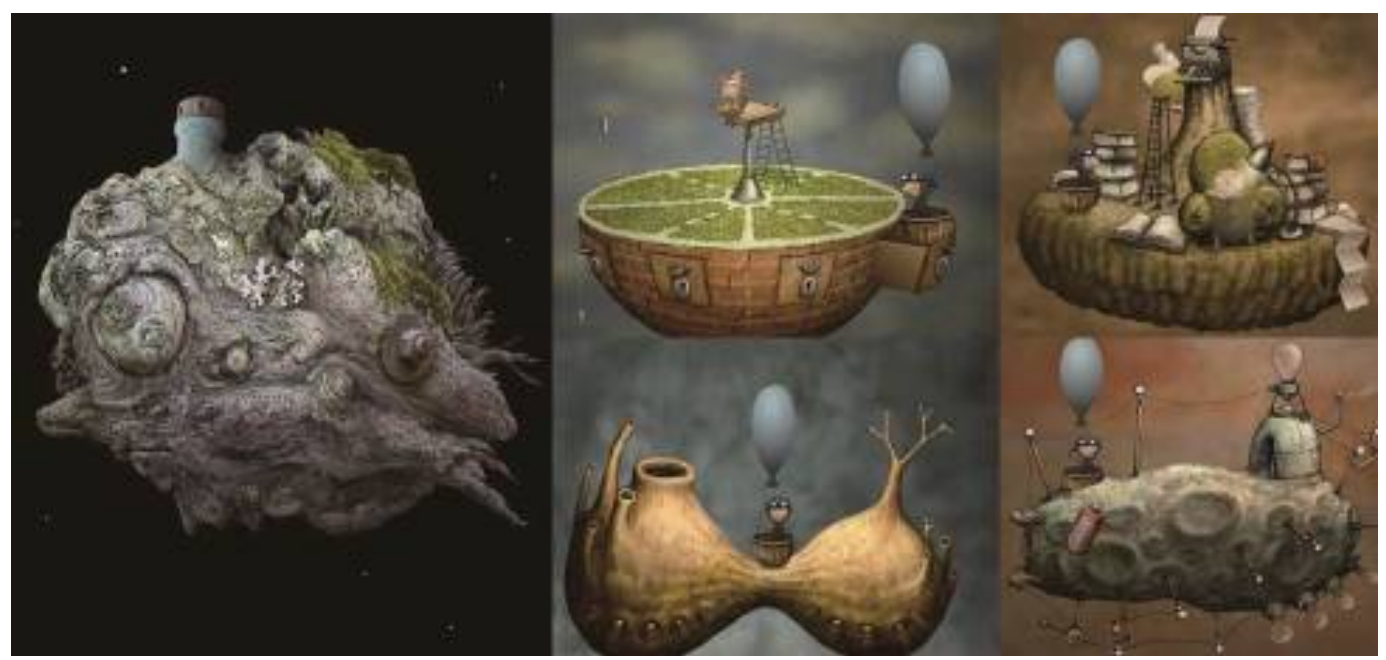

Figure 2. The scene plan of digital games Samorost 1-3.

new way.” (Freud, 1987). Being corresponding with the players’ psychology, the world, created by the designer of game modeling with a powerful and unconstrained style fantasy, frees the players from the rational and inertial thinking. Holding the desire for dreams and the impulses, the players experience a real entertainment and recreation, and thereby they are full of joyful and relaxing satisfaction. So this kind of game art gives people a feeling of familiarity and integration. The surreal game scene works of Samorost 1-3 are full of science fiction, etc., have a function of activating the atmosphere and showing vitality, under the stressful background of today's fast-paced society, work and life, the surreal fantasy modeling is most appropriate for the players to relieve and adjust their nervous and numb psychological state, and it also stimulates the senses of the players and comforts the their body and mind.

The stylized tendency in digital game scene design is the inevitable results generated by the rapid development of the game industry and the enlarged players' spiritual demands in recent years, the game designers appropriately applied the understanding of various types and genres of art to the game modeling, which can greatly enrich and improve the type and taste of game art. Game is a kind of mental activity that imitates the movement, therefore, the motion characteristics of games make the way of game become one of the important factors affecting the quality of games, and the common ways of playing games are fighting, parkour, decryption, adventure, management, intelligence, etc. In the stylized game scene design, the artistic style and game mode of the whole scene is closely related, such as the games of fighting, because their core playing method is a large amount of body collision movement, so they need nervous atmosphere and the scene of feeling of reality, which quickly bring the player into the atmosphere of the game, while today's gothic art usually shows the eerie castles, graveyard and other scenes, and this kind of atmosphere just conforms to the nervous and instable atmosphere the fighting games needed; while the games of decryption require the mysterious atmosphere, complex and realistic scenes and props design to mobilize the players' curiosity and let the decryption process full of funs. The surrealism's ideal and mysterious and unknown atmosphere exactly conforms to the requirements, and it is also one of the reasons why the game Samorost 1-3 are welcomed by many people. No matter is the gothic style, or the surrealism's formative and stylized game scene design, although they show some non-mainstream art design style, what they convey is a kind of advanced way of design thinking. Designers applies the stylized modeling to the game scene design, provides the game design with an infinite creative potential and aesthetic vision, injects an unprecedented vitality and charm, makes the game scene design present an aesthetic concept full of individual character and culture accumulation, and reflects the spirit of unremitting exploration of contemporary game designers in a special way.

\section{References}

Freud (1987). On Creative and the Unconscious (p. 42). Beijing: China Outlook Publishing House. 